\title{
Associations of Serum Cathepsin K and Polymorphisms in CTSK Gene With Bone Mineral Density and Bone Metabolism Markers in Postmenopausal Chinese Women
}

\author{
Li-hong Gao ${ }^{\dagger}$, Shan-shan $\mathrm{Li}^{\dagger}$, Hua Yue* and Zhen-lin Zhang* \\ Shanghai Clinical Research Center of Bone Diseases, Department of Osteoporosis and Bone Diseases, Shanghai Jiao Tong \\ University Affiliated Sixth People's Hospital, Shanghai, China
}

OPEN ACCESS

Edited by:

Elaine Dennison,

MRC Lifecourse Epidemiology Unit

(MRC), United Kingdom

Reviewed by:

Michaël R. Laurent,

University Hospitals Leuven, Belgium

Xiaoping Xing

Chinese Academy of Medical

Sciences and Peking Union Medical

College, China

*Correspondence:

Hua Yue

yueyinglonghua@163.com

Zhen-lin Zhang

zhangzl@sjtu.edu.cn

tThese authors have contributed equally to this work

Specialty section: This article was submitted to

Bone Research,

a section of the journa

Frontiers in Endocrinology

Received: 19 September 2019

Accepted: 27 January 2020

Published: 13 February 2020

Citation:

Gao L, Li S, Yue H and Zhang Z (2020) Associations of Serum

Cathepsin $\mathrm{K}$ and Polymorphisms in CTSK Gene With Bone Mineral

Density and Bone Metabolism

Markers in Postmenopausal Chinese Women. Front. Endocrinol. 11:48, doi: 10.3389/fendo.2020.00048
Cathepsin K plays an important role in bone resorption. The reports of the association of serum cathepsin $\mathrm{K}$ with bone mineral density (BMD) and bone turnover markers are conflicting and the role of serum cathepsin $\mathrm{K}$ as a bone turnover marker is unclear. The aims of the study were as follows: (1) to investigate the association of serum cathepsin $K$ with BMD and markers of bone turnover and (2) to evaluate the correlations of single-nucleotide polymorphisms (SNPs) within the CTSK gene with serum cathepsin $\mathrm{K}, \mathrm{BMD}$, and markers of bone metabolism in postmenopausal Chinese women. A cross-sectional study was conducted with 1752 postmenopausal Chinese women. Four tagging SNPs (rs12085336, rs12746973, rs4379678, and rs10847) of the CTSK gene were genotyped. Serum cathepsin K of 768 and markers of bone metabolism of 1752 including serum intact PTH, 25-hydroxyvitamin D [25(OH)D], procollagen type $1 \mathrm{~N}$-terminal propeptide (P1NP), and $\beta$-CrossLaps of type I collagen containing cross- linked C-telopeptide ( $\beta$-CTX) were measured. The BMD of the lumbar spine and proximal femur were measured by dual-energy $X$-ray absorptiometry (DXA). No significant relationship was detected between serum cathepsin $\mathrm{K}$ and age, BMI, BMD or bone metabolic markers (all $P>0.05$ ) after adjustment for age and BMI. We failed to identify any significant association between the genotypes or haplotypes of CTSK and BMD, bone turnover markers, or serum cathepsin K. Neither serum cathepsin K nor CTSK gene polymorphisms was correlated with BMD or bone turnover markers. Genetic polymorphisms of CTSK may not be a major contributor to variations in the serum cathepsin $\mathrm{K}$ or BMD in postmenopausal Chinese women. The results implied that serum cathepsin $\mathrm{K}$ may not be viewed as a substitute for bone turnover markers.

Keywords: cathepsin K, bone mineral density, bone metabolic markers, SNPs, postmenopausal women

\section{INTRODUCTION}

Osteoporosis is a systemic skeletal disorder characterized by decreased bone mineral density (BMD) and compromised bone microarchitecture leading to an increased risk of fracture (1). $\mathrm{BMD}$, reflecting the bone strength, is the gold standard for osteoporosis diagnosis and is one of the most important predictors of osteoporotic fracture (2). Measurement of bone turnover 
markers may reflect the cross-sectional BMD and predict the fracture, however, the results are inconsistent (3-5). Cathepsin $\mathrm{K}$ encoded by cathepsin $\mathrm{K}$ (CTSK) gene is a lysosomal cysteine proteinase involved in bone resorption and is predominantly expressed in osteoclasts. The main mechanism is that cathepsin $\mathrm{K}$ has the unique ability to cleave both helical and telopeptide regions of type 1 collagen, which comprises more than $90 \%$ of the organic matrix of bone (6). Saftig et al. (7) showed that impaired osteoclastic bone resorption leads to osteopetrosis in CTSK deficient mice. Analysis of the bones of CTSK knockout mice revealed that demineralization by osteoclasts is intact, whereas matrix degradation is significantly diminished (8). Mutations in CTSK gene are the cause of pycnodysostosis, an autosomal recessive disease characterized by osteosclerosis and short stature $(9,10)$. Specific inhibition of cathepsin $\mathrm{K}$ has therefore been a new drug target for diseases that have elevated bone resorption such as osteoporosis. ONO-5334, a low-molecular-weight synthetic inhibitor of cathepsin $\mathrm{K}$, has been shown to increase areal BMD at the hip and spine in postmenopausal osteoporosis (11-13).

Postmenopausal osteoporosis is characterized by increased bone resorption that exceeds bone formation resulting in a high bone turnover state that may be identified by measurement of biochemical markers (14). Recently, serum cathepsin K was introduced as a potential new bone turnover marker. Holzer et al. (15) reported that serum cathepsin $\mathrm{K}$ in individuals with multiple non-traumatic fractures was significantly higher than that in those without fractures, suggesting that cathepsin K could serve as a marker for fracture prediction. Meier et al. (16) found that serum cathepsin $\mathrm{K}$ appeared to reflect osteoclastic activity in patients with postmenopausal osteoporosis and Paget's disease of bone. However, the results from the study of Adolf et al. (17) which was performed in premenopausal and postmenopausal women indicated that serum cathepsin $\mathrm{K}$ levels were not suitable to differentiate women with osteoporosis from healthy subjects. So far, the results regarding the association of serum cathepsin $\mathrm{K}$ and $\mathrm{BMD}$ or bone turnover markers vary, and the specific conclusions are needed to clarified in different populations. In addition, no reports on the association of serum cathepsin $\mathrm{K}$ and $\mathrm{BMD}$ or bone turnover markers in Asian people have obtained for now, moreover, no study has been undertaken to simultaneously evaluate the serum levels of cathepsin $\mathrm{K}$ and polymorphisms in the CTSK gene. Therefore, the main objectives of this study were as follows: (1) to observe the association of serum cathepsin $\mathrm{K}$ with both $\mathrm{BMD}$ and bone metabolism markers and (2) to investigate the relationships of single-nucleotide polymorphisms (SNPs) of the CTSK gene with serum cathepsin $\mathrm{K}, \mathrm{BMD}$, and bone metabolism markers in postmenopausal Chinese women.

\section{SUBJECTS AND METHODS}

\section{Study Population}

The study was approved by the Ethics Committee of Shanghai Jiao Tong University Affiliated Sixth People's Hospital. Women who had been postmenopausal naturally for more than 1 year and were older than 50 years were eligible for the study. All the participants had a physical examination and routine laboratory measurements. Participants who received treatment for osteoporosis, drugs affect bone or vitamin D metabolism, received vitamin $\mathrm{D}$ and/or calcium supplementation within the prior 12 months, or had medical complications known to affect bone metabolism were excluded. A total number of 1799 unrelated, independent ambulatory postmenopausal female volunteers were recruited from outpatient clinics for osteoporosis. Twenty-nine subjects were excluded because they had taken alendronate or estrogen replacement therapy, and another 18 subjects were excluded for abnormal serum calcium or phosphorus levels or abnormal liver or renal function. Finally, a total of 1752 postmenopausal women (aged 50-94.9 years) were retained for this study. At the same time, 768 subjects were selected randomly by an online random number generator "wyrand" (https://github.com/wangyi-fudan/wyhash) from the whole study population for serum cathepsin $\mathrm{K}$ analysis. All participants signed an informed consent form before inclusion.

\section{BMD Measurements}

The BMD $\left(\mathrm{g} / \mathrm{cm}^{2}\right)$ of the lumbar vertebra 1-4 (L1-L4), left femoral neck, and total hip was measured using dual-energy X-ray absorptiometry (DXA) of Lunar Prodigy (GE Lunar Corp). The Lunar device was calibrated daily. The coefficient of variability $(\mathrm{CV})$ of the DXA measurements of the lumbar vertebra, femoral neck, and total hip were $1.39 \%, 2.22 \%$, and $0.70 \%$, respectively $(18,19)$. All DXA measurements were conducted by the same well-trained technologist throughout the study.

\section{Laboratory Tests}

Fasting blood samples were obtained from 8:00 to 10:00 $\mathrm{AM}$, serum samples were stored at $-80^{\circ} \mathrm{C}$ until analysis. The bone turnover markers were measured following both the manufacturer's protocol and specialized laboratory assay quality control procedures. Serum calcium (Ca), phosphorus (P), alkaline phosphatase (ALP) were measured using a Hitachi 7600-020 automatic biochemistry analyzer. The intra- and interassay CVs were $1.5 \%$ and $2.0 \%$ for $\mathrm{Ca}, 2.1 \%$ and $2.3 \%$ for $\mathrm{P}$, and $2.5 \%$ and $4.5 \%$ for ALP, respectively. Intact PTH, $25(\mathrm{OH}) \mathrm{D}$, procollagen type $1 \mathrm{~N}$-terminal propeptide (P1NP) and $\beta$-CrossLaps of type 1 collagen containing cross-linked Ctelopeptide $(\beta$-CTX) were measured using an automated Roche electro-chemiluminescence system (Roche Diagnostic $\mathrm{GmbH}$ ). The intra- and inter-assay CVs, were $1.4 \%$ and $2.9 \%$ for PTH, $5.7 \%$ and $7.3 \%$ for $25(\mathrm{OH}) \mathrm{D}, 2.9 \%$ and $3.8 \%$ for P1NP, and $2.5 \%$ and $3.5 \%$ for $\beta$-CTX, respectively $(20,21)$. Serum cathepsin K of 768 subjects selected randomly from the study population was measured using an enzyme immunoassay for the quantitative determination of cathepsin $\mathrm{K}$ in serum (Cathepsin K ELISA, Biomedica Medizinprodukte $\mathrm{GmbH}$ and $\mathrm{Co} \mathrm{KG}$, catalog number BI-20432). The intra- and inter-assay CVs were $4-6 \%$ and 6-8\%, respectively, and the detection limit was $1.1 \mathrm{pmol} / \mathrm{L}$. This assay has been validated in previous studies $(17,22)$.

\section{SNPs Selection and Genotyping}

SNPs of the CTSK gene were obtained from the dbSNP (http:// www.ncbi.nlm.nih.gov/snp/) and HapMap (http://hapmap.ncbi. 
nlm.nih.gov/) database. SNPs were selected according to the following criteria: (1) minor allele frequency (MAF) higher than $5 \%$ in the Chinese Han population; (2) classified as tagging SNPs and with pairwise linkage disequilibrium (LD) exceeding the threshold of $0.8\left(r^{2}>0.8\right)$. In all, four tagging SNPs (rs12085336, rs12746973, rs4379678, and rs10847) in CTSK gene were selected in the study. To genotype the selected tagging SNPs, genomic DNA was extracted and purified using the QuickGene DNA whole blood kit L by Nucleic Acid Isolation System (QuickGene610L, FUJI FILM, Japan). SNPs were genotyped using the ABI PRISM SNaPshot multiplex kit (Applied Biosystems), an Mx3000p real-time PCR system (Stratagene), and GeneMapper 4.1 (Applied Biosystems).

\section{Statistical Analysis}

The distribution of all continuous variables was assessed and extreme values were excluded. Descriptive statistics were given as the mean \pm SD for normally distributed data and as the median and interquartile range for the non-normally distributed data. Natural logarithmic transformation was conducted for skewed variables to approximate normality for subsequent analyses.

Hardy-Weinberg equilibrium for every SNP was checked using the $\chi^{2}$ goodness-of-fit statistic. The level of linkage disequilibrium (LD) among CTSK SNPs was assessed using Haploview version 4.2. Haplotypes were constructed from the population genotype data using the test implemented in PLINK. Quality control filtering and allele, genotype, and haplotype association tests between the adjusted parameters and SNPs were conducted using the Wald test implemented in PLINK. Multiple linear regression was used to evaluate the association between BMD, bone turnover markers, and serum cathepsin $\mathrm{K}$ and genotypes, and the association between BMD, bone turnover markers, and serum cathepsin $\mathrm{K}$ and haplotypes. The analyses were based on additive, recessive and dominant models (using $\mathrm{BMD}$, bone turnover markers, and serum cathepsin $\mathrm{K}$ as dependent variables) and adjusted for age and BMI.

A multiple linear stepwise regression analysis was performed to assess the independent contribution of the following variables to serum cathepsin K: age, BMI, markers of bone metabolism and BMD. The False Discovery Rate (FDR) method was applied to control family-wise error rate when performing multiple tests. Statistical analyses were performed using SPSS version 19.0 for Windows (SPSS Inc., Chicago, IL, USA). The threshold for the replication significance was set at $P<0.05$.

\section{RESULTS}

\section{General Characteristics of the Study Population}

The basic characteristics of the whole study population $(n=$ $1,752)$ and the participants for serum cathepsin $\mathrm{K}$ analysis $(n=$ 768) are presented in Table 1 . The participants measured serum cathepisn $\mathrm{K}$ had a similar age, $65.15 \pm 8.60$ (50-93.1) years, with the whole group $[65.38 \pm 8.98(50-94.9)$ years], and a median serum cathepsin K level of 12.29 (interquartile range 8.80-16.22) $\mathrm{pmol} / \mathrm{L}$. There was no significant difference between the two groups in the basic characteristics including age, TSM, BMI,
TABLE 1 | Clinical characteristics of participants in the study.

\begin{tabular}{lcc}
\hline Characteristics & $\begin{array}{c}\text { Subjects with serum } \\
\text { cathepsin } \mathbf{~} \\
(\boldsymbol{n}=\mathbf{7 6 8})\end{array}$ & $\begin{array}{c}\text { Total } \\
\text { sample } \\
(\boldsymbol{n}=\mathbf{1 , 7 5 2})\end{array}$ \\
\hline Age (year) & $65.52 \pm 8.44$ & $65.38 \pm 8.98$ \\
TSM (year) & $14.60(8.90-22.30)$ & $15.00(9.00-22.60)$ \\
BMl (kg/m $\left.{ }^{2}\right)$ & $23.43 \pm 3.30$ & $23.47 \pm 3.29$ \\
Lumbar 1-4 BMD $\left(\mathrm{g} / \mathrm{cm}^{2}\right)$ & $0.89 \pm 0.14$ & $0.88 \pm 0.14$ \\
Femoral neck BMD $\left(\mathrm{g} / \mathrm{cm}^{2}\right)$ & $0.73 \pm 0.11$ & $0.72 \pm 0.11$ \\
Total hip BMD $\left(\mathrm{g} / \mathrm{cm}^{2}\right)$ & $0.77 \pm 0.12$ & $0.77 \pm 0.12$ \\
PTH $(\mathrm{pg} / \mathrm{mL})$ & $41.04(32.01-52.61)$ & $40.66(32.06-51.98)$ \\
25(OH)D (ng/mL) & $21.76(17.26-26.94)$ & $18.29(13.29-23.84)$ \\
Ca (mmol/L) & $2.32 \pm 0.10$ & $2.34 \pm 0.12$ \\
P (mmol/L) & $1.16 \pm 0.14$ & $1.16 \pm 0.15$ \\
ALP $(\mathrm{U} / \mathrm{L})$ & $72.00(60.00-86.00)$ & $73.00(62.00-88.00)$ \\
P1NP (ng/mL) & $57.90(43.90-75.41)$ & $56.94(43.36-74.33)$ \\
$\beta$-CTX (ng/L) & $420.00(296.00-559.5)$ & $410.00(284.00-558.00)$ \\
CTSK (pmol/L) & $12.29(8.80-16.22)$ &
\end{tabular}

Normally distributed data are shown as the mean $\pm S D$, data that are not normally distributed data are shown as the median (interquartile range). TSM, time since menopause; BMI, body mass index; BMD, bone mineral density.

BMD of lumber 1-4, femoral neck and total hip, PTH, 25(OH)D, $\mathrm{Ca}, \mathrm{P}, \mathrm{ALP}, \mathrm{P} 1 \mathrm{NP}, \beta$-CTX, serum albumin, creatinine, or urea nitrogen. In the overall study population of 1752, the subjects with osteoporosis, osteopenia and normal bone mass were 588 , 867 , and 297, respectively, and the number of that in the $n=768$ subgroup were 232,377 , and 159 , respectively.

\section{Associations of Serum Cathepsin K With Markers of Bone Metabolism and BMD}

The serum cathepsin K concentrations were measured in 768 participants selected randomly from the whole study population. In the overall population of 1752, we found that both $\beta$-CTX and P1NP have a significant relationship with BMD of L1L4, left femoral neck, and total hip (all $P<0.05$ ). In the $n$ $=768$ subgroup, significant relationship was detected between $\beta$-CTX and P1NP and BMD of left femoral neck, and total hip (all $P<0.05$ ). However, we failed to identify any significant association between BMD of L1-L4 and $\beta$-CTX or P1NP (all $P>0.05)$. Multiple linear regression analysis was performed using serum cathepsin $\mathrm{K}$ as the dependent variable and age, BMI, serum $\beta$-CTX, P1NP, PTH, 25(OH)D, ALP, BMD of the L1-L4, femoral neck and total hip as the independent variable in the subjects (Table 2). It is found that serum cathepsin $\mathrm{K}$ level was positively associated with the serum 25(OH)D of the studied postmenopausal women $(P=0.049)$, however, the significance disappeared after adjustment for age and BMI $(P$ $=0.053)$. No association was found between serum cathepsin $\mathrm{K}$ and age, BMI, or between serum cathepsin $\mathrm{K}$ and serum P1NP, $\beta$-CTX, PTH, ALP, or $25(\mathrm{OH}) \mathrm{D}$, or between the serum cathepsin $\mathrm{K}$ and BMD of L1-4, femoral neck or total hip (all $P>0.05$ ) (Table 2). 


\section{Allele Frequencies and Haplotype Structures}

Four SNPs in the CTSK gene of 1752 unrelated postmenopausal Chinese women were genotyped in the study. Information of four SNPs is shown in Table 3. The genotyping success rate for all SNPs exceeded 95\%. Overall, 4 polymorphisms of CTSK gene had a MAF at least 0.116 in this study and the genotype frequencies of all 4 SNPs were compatible with the HardyWeinberg equilibrium (HWE) $(P>0.05)$. LD was measured by Haploview software to calculate the D' value which represent the strength of each pairwise comparison of biallelic SNPs. In CTSK, we distinguished one block with high LD (all D'=1.0) containing rs12085336, rs12746973, rs4379678, and rs10847. On the basis of these polymorphisms, significant LD was observed across the gene and we inferred the existence of 5 haplotypes in the block,

TABLE 2 | Correlations between serum CTSK and other anthropometric and clinical data.

\begin{tabular}{|c|c|c|c|c|}
\hline & $\begin{array}{c}\text { Standardized } \\
\beta \text {-Coefficients }\end{array}$ & $P$-value & $\begin{array}{c}\text { Standardized } \\
\beta \text {-Coefficients }\end{array}$ & $P$-value ${ }^{a}$ \\
\hline Age (year) & -0.034 & 0.343 & & \\
\hline $\mathrm{BMl}\left(\mathrm{kg} / \mathrm{m}^{2}\right)$ & -0.015 & 0.673 & & \\
\hline Lumbar 1-4 BMD $\left(\mathrm{g} / \mathrm{cm}^{2}\right)$ & 0.047 & 0.201 & 0.045 & 0.227 \\
\hline $\begin{array}{l}\text { Femoral neck BMD } \\
\left(\mathrm{g} / \mathrm{cm}^{2}\right)\end{array}$ & -0.023 & 0.530 & -0.050 & 0.237 \\
\hline Total hip BMD $\left(\mathrm{g} / \mathrm{cm}^{2}\right)$ & -0.009 & 0.796 & -0.027 & 0.528 \\
\hline$\beta-C T X(n g / L)$ & 0.029 & 0.432 & 0.026 & 0.467 \\
\hline P1NP (ng/mL) & 0.041 & 0.253 & 0.038 & 0.293 \\
\hline PTH (pg/mL) & 0.017 & 0.629 & 0.024 & 0.519 \\
\hline ALP (U/L) & 0.014 & 0.772 & 0.016 & 0.741 \\
\hline $25(\mathrm{OH}) \mathrm{D}(\mathrm{ng} / \mathrm{mL})$ & 0.071 & 0.049 & 0.070 & 0.053 \\
\hline
\end{tabular}

Significant values $(P<0.05)$ are presented in bold.

${ }^{a}$ Adjusted for age and BMI.
TGTC, AGCC, AGTT, AATC, and AGTC with frequencies of $0.338,0.231,0.204,0.117$, and 0.110 , respectively.

\section{Associations Between Genotypes and Haplotypes of CTSK and Serum Cathepsin $\mathrm{K}$, Markers of Bone Metabolism and BMD}

We investigated the association between four SNPs and five haplotypes of CTSK gene and serum cathepsin K in 768 subjects, and the association between four SNPs and five haplotypes and bone metabolism markers and BMD of L1-L4, femoral neck and total hip in 1752 subjects using PLINK. We performed multiple liner regression and adjusted all the variables for age and BMI. Haplotype AGTC of CTSK was found to be significantly associated with BMD of L1-4 $(P=0.019)$ (Table 4) and SNP rs12746973 was confirmed to be significantly associated with variations in the serum P1NP levels $(P=0.032)$ adjusted for age and BMI (Table 5). However, both the significant correlation disappeared after applying a FDR correction. No association was found between the other bone metabolism markers or BMD of femoral neck or total hip and any of four SNPs or five haplotypes of the CTSK gene (data not shown). In addition, there was no association between any of the four SNPs or five haplotypes of CTSK gene and serum cathepsin $\mathrm{K}$ levels of the 768 postmenopausal women in our study (Table 6).

\section{DISCUSSION}

To our knowledge, this is the first study reported a populationbased association analysis of both CTSK gene polymorphism and serum cathepsin K and BMD, bone metabolic markers. Although CTSK has been shown to plays a crucial role in the regulation of bone density by both its link with the monogenic disorder pychodysostosis and by manipulation of CTSK expression in vivo in animal models, as well as to serve as a predictor of bone loss or non-traumatic fracture, we failed to find significant

TABLE 3 | Information of the four studied SNPS.

\begin{tabular}{|c|c|c|c|c|c|c|c|}
\hline SNPs in dbSNP & Chr & Position & Region & SNP & $\begin{array}{c}\text { MAF } \\
\text { (this study) }\end{array}$ & $\begin{array}{c}\text { MAF } \\
\text { (hapmap-HCB) }\end{array}$ & $\begin{array}{c}\text { MAF } \\
\text { (hapmap-CEU) }\end{array}$ \\
\hline rs12085336 & 1 & 150775780 & intron 5 & $\mathrm{~A} / \mathrm{T}$ & 0.338 & 0.357 & 0.373 \\
\hline rs12746973 & 1 & 150779401 & intron 1 & $\mathrm{G} / \mathrm{A}$ & 0.116 & 0.106 & 0.053 \\
\hline rs4379678 & 1 & 150780582 & intron 1 & $\mathrm{C} / \mathrm{T}$ & 0.233 & 0.241 & 0.083 \\
\hline rs10847 & 1 & 150782797 & 5'-flanking & $\mathrm{C} / \mathrm{T}$ & 0.205 & 0.211 & 0.225 \\
\hline
\end{tabular}

TABLE 4 | Associations between four SNPs, five haplotypes of CTSK, and the BMD of lumber spine 1-4 in this study.

\begin{tabular}{|c|c|c|c|c|c|c|c|}
\hline SNP & BETA & $R^{2}$ & $P$-value ${ }^{a}$ & haplotype & BETA & $R^{2}$ & $P$-value ${ }^{a}$ \\
\hline rs12085336 & -0.007 & $9.775 e-005$ & 0.192 & AGTT & -0.002 & 0.0003 & 0.749 \\
\hline rs12746973 & -0.021 & $5.809 \mathrm{e}-006$ & 0.193 & AGCC & 0.001 & 4.039e-005 & 0.807 \\
\hline rs4379678 & 0.009 & $5.135 e-005$ & 0.244 & AATC & -0.001 & 5.899e-005 & 0.944 \\
\hline \multirow[t]{2}{*}{ rs10847 } & 0.009 & 0.0062 & 0.338 & TGTC & -0.007 & 0.0001 & 0.152 \\
\hline & & & & AGTC & 0.018 & 0.0004 & 0.019 \\
\hline
\end{tabular}

Significant values $(P<0.05)$ are presented in bold. BETA regression coefficient, $R^{2} r$-suqared regression coefficient, ${ }^{a}$ adjusted for age and BMI. 
TABLE 5 | Associations between four SNPs, five haplotypes of CTSK, and serum P1NP in this study.

\begin{tabular}{|c|c|c|c|c|c|c|c|}
\hline SNP & BETA & $R^{2}$ & $P$-value ${ }^{a}$ & haplotype & BETA & $R^{2}$ & $P$-value ${ }^{a}$ \\
\hline rs12085336 & 0.020 & 8.368e-006 & 0.583 & AGTT & 0.072 & 0.0015 & 0.067 \\
\hline rs12746973 & -0.219 & 2.346e-005 & 0.032 & AGCC & -0.040 & 0.0004 & 0.265 \\
\hline rs4379678 & -0.042 & 0.0004 & 0.385 & AATC & -0.034 & $2.035 e-005$ & 0.483 \\
\hline \multirow[t]{2}{*}{ rs10847 } & 0.082 & 0.0015 & 0.187 & TGTC & 0.011 & $5.087 e-006$ & 0.737 \\
\hline & & & & AGTC & -0.028 & 0.0002 & 0.571 \\
\hline
\end{tabular}

Significant values $(P<0.05)$ are presented in bold. BETA regression coefficient, $R^{2}$ r-suqared regression coefficient, a adjusted for age and BMI.

TABLE 6 | Associations between four SNPs, five haplotypes of CTSK, and serum CTSK in this study.

\begin{tabular}{|c|c|c|c|c|c|c|c|}
\hline SNP & BETA & $R^{2}$ & $P$-value ${ }^{a}$ & haplotype & BETA & $R^{2}$ & $P$-value ${ }^{a}$ \\
\hline rs12085336 & -0.223 & 0.0011 & 0.760 & AGTT & -0.275 & 0.0005 & 0.495 \\
\hline rs12746973 & -0.532 & 0.0004 & 0.165 & AGCC & 0.563 & 0.0014 & 0.308 \\
\hline rs4379678 & 1.757 & 0.0014 & 0.242 & AATC & -0.162 & 0.0004 & 0.646 \\
\hline \multirow[t]{2}{*}{ rs10847 } & -0.900 & 0.0005 & 0.094 & TGTC & 0.384 & 0.0011 & 0.383 \\
\hline & & & & AGTC & -0.260 & 0.0003 & 0.642 \\
\hline
\end{tabular}

BETA regression coefficient, $R^{2} r$-suqared regression coefficient, a adjusted for age and BMI.

association between serum cathepsin $\mathrm{K}$ and $\mathrm{BMD}$ or bone metabolic markers levels. Besides, we were unable to show a clear association between CTSK polymorphisms and BMD, serum cathepsin $\mathrm{K}$ levels or bone turnover markers in postmenopausal Chinese women.

Because cathepsin $\mathrm{K}$ plays a critical role in osteoclastmediated bone degradation by degrading type 1 collagen and osteonectin, major components of the organic matrix of bone, a correlation between higher serum cathepsin K and osteoporosis, increased bone turnover or osteoporotic fracture might be expected. Results from the previous studies demonstrated that the cathepsin $\mathrm{K}$ concentrations in subjects with multiple nontraumatic fractures were significantly higher than that in those without fractures and the cathepsin $\mathrm{K}$ levels of patients with osteoporosis and Paget's disease of bone were significantly higher than that of healthy controls $(15,16)$. Munoz-Torres et al. (23) observed that serum cathepsin $\mathrm{K}$ levels were higher in 46 postmenopausal women with osteoporosis $(9.4 \pm 11$ $\mathrm{pmol} / \mathrm{L})$ compared with 20 healthy postmenopausal women $(6.8 \pm 8.1 \mathrm{pmol} / \mathrm{L} ; P<0.01)$ and 20 pre-menopausal women $(6.3 \pm 5.0 \mathrm{pmol} / \mathrm{L}, P<0.01)$. Besides, baseline concentrations of cathepsin $\mathrm{K}$ were negatively correlated with BMD at the femoral neck in osteoporotic women and serum cathepsin $\mathrm{K}$ decreases gradually after alendronate treatment. These results suggested that the serum level of cathepsin $\mathrm{K}$ could serve as a marker of osteoclast activity and predictor for fracture and BMD. However, in our study, we failed to find any association between serum cathepsin $\mathrm{K}$ and $\mathrm{BMD}$ of lumbar spine or hip of the participants and that was consistent with the results from Prezelj et al. (24), although they reported that serum cathepsin K levels was significant correlation with change in femoral neck BMD in a population of healthy non-osteoporotic women followed up for 3 years, serum levels of cathepsin $\mathrm{K}$ did not correlate significantly with either spinal BMD change or cross-sectional BMD of the spine or femoral neck. The varied results of these studies can be attributed to many explanations. The population sizes were relatively small in these studies, dozens or no more than 200 subjects were included, and the small sample size would limit the power to prove relationships and differences. The participants in these studies were various, including participants with and without osteoporotic fracture, postmenopausal osteoporosis, healthy non-osteoporotic pre-, peri, early postmenopausal women. Therefore, the conditions of bone metabolism of these subjects were various as there would be significantly accelerated bone turnover rate and reduced $\mathrm{BMD}$ during the menopausal periods due to the serum estrogen levels dramatically decrease within a short time in women (25). In addition, although cathepsin $\mathrm{K}$ is expressed at very high levels in osteoclasts, it is also synthesized in other tissues and may play important roles in processes other than bone resorption. Cathepsin $\mathrm{K}$ expression has also been found in normal bronchial epithelial cells (26), thyroid epithelial cells (27), synovial fibroblasts of patients with rheumatoid arthritis (28), breast carcinoma cells (29), osteoblast (30) and chordoma (31). Zhao et al. (32) found that circulating cathepsin $\mathrm{K}$ increased in patients with chronic heart failure. Therefore, serum cathepsin $\mathrm{K}$ level may not necessarily reflect cathepsin $\mathrm{K}$ expressed in osteoclasts and could be affected by other pathophysiologic processes. Besides, Dodds et al. (33) found that cathepsin K processing and polarization occurs as the osteoclast approaches bone, and its activation occurs intracellularly, before secretion into the resorption lacunae and the onset of bone resorption, implying that local factors in the microenvironment may regulate these events, for instance, phosphatidylinositol 3-kinases (34). It is found that the sections of osteoclastoma, which included abundant osteoclasts distant from bone formation sites, 
showed intense expression of cathepsin K mRNA, high levels of procathepsin $\mathrm{K}$, but negligible levels of mature cathepsin $\mathrm{K}$, and this population of osteoclasts showed no cathepsin activity. It means that serum cathepsin $\mathrm{K}$ levels may not reflect the osteoclast numbers and it remains to be determined whether this variable expression pattern reflects transcriptional regulation of the cathepsin K gene potentially at different stages of osteoclast function (33). In addition, BMD assessed by DXA measures the total bone mineral content in a projected area (integral areal BMD) and cannot directly measure other skeletal features that may also contribute to bone strength, such as the relative amounts of cortical and trabecular bone. Further studies are needed to clarify the association between the serum cathepsin K and BMD that measured by quantitative computed tomography (QCT) which could provide a direct measurement of cortical and trabecular volumetric BMD, both of which may contribute to bone strength and fracture risk (35).

Biochemical markers of resorption and formation that provide sensitive and dynamic indices of bone metabolic may be a useful investigation tool for quantifying and monitoring the effects of anti-osteoporotic drugs on bone cells (5). In this study, there was no association detected between serum cathepsin $\mathrm{K}$ levels and bone metabolic markers, such as $\beta$-CTX or P1NP in postmenopausal Chinese women. This is in line with the results of the studies reported before $(15,17,22,24)$. The results imply that serum cathepsin $\mathrm{K}$ may not be viewed as a substitute for current bone turnover markers.

In the study, we failed to find any correlation of serum cathepsin $\mathrm{K}$ with age of the postmenopausal Chinese women. This is consistent with the previous published studies $(16,23,24)$. It is indicated that aging might not be an influencing factor in serum cathepsin $\mathrm{K}$ concentration in postmenopausal women.

Osteoporosis is a complex, common disease that results from genetic and environmental causes. Depending on recent studies, many novel genetic loci have been identified as being associated with BMD or osteoporosis (36-38). Given the increasing body of evidence linking CTSK with the regulation of BMD, we hypothesized that variation in CTSK can result in consequent variation in BMD. Therefore, we tested CTSK polymorphisms for possible association with BMD, bone turnover markers and serum cathepsin $\mathrm{K}$ in postmenopausal Chinese women. However, there was no significant association detected between four SNPs or five haplotypes and adjusted BMD of L1-4, femoral neck or total hip in this study. These results were consistent with that of Giraudeau et al. (39), who studied the association of CTSK gene polymorphisms with BMD in a large cohort of perimenopausal women $(\sim 3000)$ from Scotland, and were unable to show a clear association between CTSK polymorphisms and BMD. It is considered that CTSK polymorphisms that induce even minor coding or expression changes may have enough deleterious impact on fitness to induce negative selection of such polymorphisms and prevent them from reaching an appreciable frequency and possibly eliminate them from the population over time (39). This may be the reason why we did not find any coding change SNPs with frequencies above 5\%, although we extensively screened the entire CTSK gene range and regulatory region. The SNPs in our study were located in intron and $5^{\prime}$-flanking in the CTSK gene. However, these SNPs may have strong LD with others within the same exons. Studies have shown that intronic variants may also have functional significance, for example, they could affect the splicing of cryptic exons (40). Another possible reason for failure to observe association of CTSK polymorphism with $\mathrm{BMD}$ is that unknown environmental factors may be confounding correlation between CTSK genotypes or haplotypes and $\mathrm{BMD}$, thereby masking the presence of a significant genetic association. Thus, CTSK gene common polymorphism may not be a major contributor to BMD variation in postmenopausal Chinese women, although further studies are needed to prove the findings.

There were some limitations in our study. First, the number of subjects in our study was moderate, especially those who measured serum cathepsin K levels. Due to the high prevalence of osteoporosis in the postmenopausal Chinese women visiting our outpatient clinics, we failed to obtain the results of the differences of serum cathepsin $\mathrm{K}$ levels between subjects with postmenopausal osteoporosis and healthy postmenopausal controls. Second, the population studied was limited to postmenopausal women, the results of correlation of serum cathepsin K levels or SNPs of CTSK gene with BMD or bone metabolic markers in men and younger women could not be afforded. It is of great importance to investigate the association between serum cathepsin K levels or SNPs of CTSK gene with $\mathrm{BMD}$ or bone metabolic markers in young healthy population, particularly those who with peak BMD. Apart from that, high prevalence of vitamin $\mathrm{D}$ insufficient/deficient in the study subjects, which may have an influence on the findings. Besides, this is a cross-sectional study and could not evaluate the predictor effect of serum cathepsin $\mathrm{K}$ on $\mathrm{BMD}$ change or the risk of osteoporotic fracture. Additionally, we cannot assess the impact that rare variants in CTSK gene might have on BMD in our study because we restricted our analysis to tagging SNPs with an MAF $>5 \%$. Future studies are needed to consider other types of polymorphisms such as insertion-deletions, copy number variants, and less common SNPs $(<5 \% \mathrm{MAF})$ as well as interactions between genes and environmental factors in order to better account for the phenotypic variation in BMD.

In conclusion, the results of our study indicated that serum cathepsin $\mathrm{K}$ was not correlated to $\mathrm{BMD}$ or bone metabolic markers. In addition, common genetic polymorphisms in CTSK gene may not be a major contributor to serum cathepsin $\mathrm{K}$ or $\mathrm{BMD}$ in postmenopausal Chinese women.

\section{DATA AVAILABILITY STATEMENT}

The datasets analyzed for this study can be found in the European Variation Archive (https://www.ebi.ac.uk/ena/data/ view/PRJEB36082).

\section{ETHICAL STATEMENT}

The study has been approved by the Ethics Committee of Shanghai Jiao Tong University Affiliated Sixth People's Hospital. All procedures performed in the study were in 
accordance with the ethical standards of the Ethics Committee of Shanghai Jiao Tong University Affiliated Sixth People's Hospital and with the 1964 Helsinki declaration and its later amendments or comparable ethical standards. Informed consent was obtained from all individual participants included in the study.

\section{AUTHOR CONTRIBUTIONS}

LG and SL conducted the study and analyzed the data. LG wrote the draft manuscript. ZZ and HY supervised the study

\section{REFERENCES}

1. Kanis JA, Melton LJ III, Christiansen C, Johnston CC, Khaltaev N. The diagnosis of osteoporosis. J Bone Miner Res. (1994) 9:1137-41. doi: 10.1002/jbmr.5650090802

2. Kanis JA, Oden A, Johnell O, Johansson H, De Laet C, Brown J, et al. The use of clinical risk factors enhances the performance of BMD in the prediction of hip and osteoporotic fractures in men and women. Osteoporos Int. (2007) 18:1033-46. doi: 10.1007/s00198-007-0343-y

3. Ebeling PR, Atley LM, Guthrie JR, Burger HG, Dennerstein L, Hopper JL,et al. Bone turnover markers and bone density across the menopausal transition. $J$ Clin Endocrinol Metab. (1996) 81:3366-71. doi: 10.1210/jcem.81.9.8784098

4. Gerdhem P, Ivaska KK, Alatalo SL, Halleen JM, Hellman J, Isaksson A, et al. Biochemical markers of bone metabolism and prediction of fracture in elderly women. J Bone Miner Res. (2004) 19:386-93. doi: 10.1359/JBMR.0301244

5. Delmas PD, Eastell R, Garnero P, Seibel MJ, Stepan J. The use of biochemical markers of bone turnover in osteoporosis. Committee of Scientific Advisors of the International Osteoporosis Foundation. Osteoporos Int. (2000)11 (Suppl. 6):S2-17 doi: 10.1007/s001980070002

6. Garnero P, Borel O, Byrjalsen I, Ferreras M, Drake FH, McQueney MS, et al. The collagenolytic activity of cathepsin $\mathrm{K}$ is unique among mammalian proteinases. J Biol Chem. (1998) 273:32347-52. doi: 10.1074/jbc.273.48.32347

7. Saftig P, Hunziker E, Wehmeyer O, Jones S, Boyde A, Rommerskirch $\mathrm{W}$, et al. Impaired osteoclastic bone resorption leads to osteopetrosis in cathepsin-K-deficient mice. Proc Natl Acad Sci USA. (1998) 95:13453-58. doi: 10.1073/pnas.95.23.13453

8. Gowen M, Lazner F, Dodds R, Kapadia R, Feild J, Tavaria M, et al. Cathepsin K knockout mice develop osteopetrosis due to a deficit in matrix degradation but not demineralization. J Bone Miner Res. (1999) 14:1654-63. doi: 10.1359/jbmr.1999.14.10.1654

9. Gelb BD, Shi GP, Chapman HA, Desnick RJ. Pycnodysostosis, a lysosomal disease caused by cathepsin K deficiency. Science. (1996) 273:1236-8. doi: 10.1126/science.273.5279.1236

10. Zheng H, Zhang Z, He JW, Fu WZ, Zhang ZL. A novel mutation (R122Q) in the cathepsin K gene in a Chinese child with Pyknodysostosis. Gene. (2013) 521:176-9. doi: 10.1016/j.gene.2013.03.014

11. Engelke K, Nagase S, Fuerst T, Small M, Kuwayama T, Deacon S, et al. The effect of the cathepsin K inhibitor ONO-5334 on trabecular and cortical bone in postmenopausal osteoporosis: the OCEAN study. J Bone Miner Res. (2014) 29:629-38. doi: 10.1002/jbmr.2080

12. Eastell R, Nagase S, Small M, Boonen S, Spector T, Ohyama M, et al. Effect of ONO-5334 on bone mineral density and biochemical markers of bone turnover in postmenopausal osteoporosis: 2-year results from the OCEAN study. J Bone Miner Res. (2014) 29:458-66. doi: 10.1002/jbmr.2047

13. Eastell R, Nagase S, Ohyama M, Small M, Sawyer J, Boonen S, et al. Safety and efficacy of the cathepsin $\mathrm{K}$ inhibitor ONO-5334 in postmenopausal osteoporosis: the OCEAN study. J Bone Miner Res. (2011) 26:1303-12. doi: 10.1002/jbmr.341

14. Manolagas SC. Birth and death of bone cells: basic regulatory mechanisms and implications for the pathogenesis and treatment of osteoporosis. Endocr Rev. (2000) 21:115-37. doi: 10.1210/edrv.21.2.0395 and revised the manuscript. All authors read and approved the final manuscript.

\section{ACKNOWLEDGMENTS}

We thank all the participants for their invaluable cooperation. The study was supported by Foundation of Shanghai Municipal Health Commission (2015401870), National Natural Science Foundation of China (NSFC) (Nos. 81770874 and 81974126), and Science and Technology Commission of Shanghai Municipality (16ZR1425700).

15. Holzer G, Noske H, Lang T, Holzer L, Willinger U. Soluble cathepsin K: a novel marker for the prediction of nontraumatic fractures? J Lab Clin Med. (2005) 146:13-7. doi: 10.1016/j.lab.2005.03.016

16. Meier C, Meinhardt U, Greenfield JR, De Winter J, Nguyen TV, Dunstan CR, et al. Serum cathepsin K concentrations reflect osteoclastic activity in women with postmenopausal osteoporosis and patients with Paget's disease. Clin Lab. (2006) 52:1-10.

17. Adolf D, Wex T, Jahn O, Riebau C, Halangk W, Klose S, et al. Serum cathepsin $\mathrm{K}$ levels are not suitable to differentiate women with chronic bone disorders such as osteopenia and osteoporosis from healthy pre- and postmenopausal women. Maturitas. (2012) 71:169-72. doi: 10.1016/j.maturitas.2011.11.024

18. Zhang H, He JW, Gao G, Yue H, Yu JB, Hu WW, et al. Polymorphisms in the HOXD4 gene are not associated with peak bone mineral density in Chinese nuclear families. Acta Pharmacol Sin. (2010) 31:977-83. doi: 10.1038/aps.2010.91

19. Gao G, Zhang ZL, Zhang H, Hu WW, Huang QR, Lu JH, et al. Hip axis length changes in 10,554 males and females and the association with femoral neck fracture. J Clin Densitom. (2008) 11:360-6. doi: 10.1016/j.jocd.2008. 04.005

20. Lu HK, Zhang Z, Ke YH, He JW, Fu WZ, Zhang CQ, et al. High prevalence of vitamin $\mathrm{D}$ insufficiency in China: relationship with the levels of parathyroid hormone and markers of bone turnover. PLoS ONE. (2012) 7:e47264. doi: 10.1371/journal.pone.0047264

21. He J, Zhang H, Wang C, Zhang Z, Yue H, Hu W, et al. Associations of serum sclerostin and polymorphisms in the SOST gene with bone mineral density and markers of bone metabolism in postmenopausal Chinese women. J Clin Endocrinol Metab. (2014) 99:E665-73. doi: 10.1210/jc.2013-2086

22. Kerschan-Schindl K, Hawa G, Kudlacek S, Woloszczuk W, Pietschmann P. Serum levels of cathepsin $\mathrm{K}$ decrease with age in both women and men. Exp Gerontol. (2005) 40:532-5. doi: 10.1016/j.exger.2005.04.001

23. Munoz-Torres M, Reyes-Garcia R, Mezquita-Raya P, Fernandez-Garcia D, Alonso G, de Luna JD, et al. Serum cathepsin K as a marker of bone metabolism in postmenopausal women treated with alendronate. Maturitas. (2009) 64:188-92. doi: 10.1016/j.maturitas.2009.09.011

24. Prezelj J, Ostanek B, Logar DB, Marc J, Hawa G, Kocjan T. Cathepsin $\mathrm{K}$ predicts femoral neck bone mineral density change in nonosteoporotic peri- and early postmenopausal women. Menopause. (2008) 15:369-73. doi: 10.1097/gme.0b013e3181271873

25. Riggs BL, Khosla S, Melton LJ III. Sex steroids and the construction and conservation of the adult skeleton. Endocr Rev. (2002) 23:279-302. doi: 10.1210/edrv.23.3.0465

26. Buhling F, Waldburg N, Gerber A, Hackel C, Kruger S, Reinhold D, et al. Cathepsin K expression in human lung. Adv Exp Med Biol. (2000) 477:281-6. doi: 10.1007/0-306-46826-3_30

27. Tepel C, Bromme D, Herzog V, Brix K. Cathepsin K in thyroid epithelial cells: sequence, localization and possible function in extracellular proteolysis of thyroglobulin. J Cell Sci. (2000) 113 (Pt 24):4487-98.

28. Hummel KM, Petrow PK, Franz JK, Muller-Ladner U, Aicher WK, Gay RE, et al. Cysteine proteinase cathepsin $\mathrm{K}$ mRNA is expressed in synovium of patients with rheumatoid arthritis and is detected at sites of synovial bone destruction. J Rheumatol. (1998) 25:1887-94. 
29. Littlewood-Evans AJ, Bilbe G, Bowler WB, Farley D, Wlodarski B, Kokubo T, et al. The osteoclast-associated protease cathepsin $\mathrm{K}$ is expressed in human breast carcinoma. Cancer Res. (1997) 57:5386-90.

30. Mandelin J, Hukkanen M, Li TF, Korhonen M, Liljestrom M, Sillat T, et al. Human osteoblasts produce cathepsin K. Bone. (2006) 38:76977. doi: 10.1016/j.bone.2005.10.017

31. Haeckel C, Krueger S, Kuester D, Ostertag H, Samii M, Buehling F, et al. Expression of cathepsin K in chordoma. Hum Pathol. (2000) 31:834-40. doi: 10.1053/hupa.2000.8448

32. Zhao G, Li Y, Cui L, Li X, Jin Z, Han X, et al. Increased circulating cathepsin $\mathrm{K}$ in patients with chronic heart failure. PLoS ONE. (2015) 10:e0136093. doi: 10.1371/journal.pone.0136093

33. Dodds RA, James IE, Rieman D, Ahern R, Hwang SM, Connor JR, et al. Human osteoclast cathepsin $\mathrm{K}$ is processed intracellularly prior to attachment and bone resorption. J Bone Miner Res. (2001) 16:478-86. doi: 10.1359/jbmr.2001.16.3.478

34. Rieman DJ, McClung HA, Dodds RA, Hwang SM, Holmes MW, James IE, et al. Biosynthesis and processing of cathepsin $\mathrm{K}$ in cultured human osteoclasts. Bone. (2001) 28:282-9. doi: 10.1016/S8756-3282(00)00445-2

35. Black DM, Bouxsein ML, Marshall LM, Cummings SR, Lang TF, Cauley JA, et al. Proximal femoral structure and the prediction of hip fracture in men: a large prospective study using QCT. J Bone Miner Res. (2008) 23:1326-33. doi: 10.1359/jbmr.080316

36. Styrkarsdottir U, Halldorsson BV, Gretarsdottir S, Gudbjartsson DF, Walters GB, Ingvarsson T, et al. Multiple genetic loci for bone mineral density and fractures. N Engl J Med. (2008) 358:2355-65. doi: 10.1056/NEJMoa0801197
37. Liu JM, Zhang MJ, Zhao L, Cui B, Li ZB, Zhao HY, et al. Analysis of recently identified osteoporosis susceptibility genes in Han Chinese women. J Clin Endocrinol Metab. (2010) 95:E112-20. doi: 10.1210/jc.2009-2768

38. Wang $\mathrm{C}$, Zhang $\mathrm{Z}$, Zhang $\mathrm{H}, \mathrm{He} J W, \mathrm{Gu} J M, \mathrm{Hu} W W$, et al. Susceptibility genes for osteoporotic fracture in postmenopausal Chinese women. J Bone Miner Res. (2012) 27:2582-91. doi: 10.1002/jb mr.1711

39. Giraudeau FS, McGinnis RE, Gray IC, O’Brien EJ, Doncaster KE, Spurr $\mathrm{NK}$, et al. Characterization of common genetic variants in cathepsin $\mathrm{K}$ and testing for association with bone mineral density in a large cohort of perimenopausal women from Scotland. J Bone Miner Res. (2004) 19:31-41. doi: 10.1359/jbmr.0301205

40. Pagani F, Baralle FE. Genomic variants in exons and introns: identifying the splicing spoilers. Nat Rev Genet. (2004) 5:389-96. doi: 10.1038/nr g1327

Conflict of Interest: The authors declare that the research was conducted in the absence of any commercial or financial relationships that could be construed as a potential conflict of interest.

Copyright (C) $2020 \mathrm{Gao}, \mathrm{Li}$, Yue and Zhang. This is an open-access article distributed under the terms of the Creative Commons Attribution License (CC BY). The use, distribution or reproduction in other forums is permitted, provided the original author(s) and the copyright owner(s) are credited and that the original publication in this journal is cited, in accordance with accepted academic practice. No use, distribution or reproduction is permitted which does not comply with these terms. 